\title{
Biological Therapies for Rheumatoid Arthritis: An Overview for the Clinician
}

\author{
Kate E Findeisen ${ }^{\mathrm{I} *}$ \\ Julia Sewell ${ }^{1, *}$ \\ Andrew JK Ostor ${ }^{2,3}$ \\ 'The Alfred Hospital, Melbourne, \\ Victoria, Australia; ${ }^{2}$ Cabrini Medical \\ Centre, Melbourne, Victoria, Australia; \\ ${ }^{3}$ Monash University, Melbourne, Victoria, \\ Australia \\ *These authors contributed equally to \\ this work
}

\begin{abstract}
Rheumatoid arthritis (RA) is a disease characterised by inflammation of synovial joints and poses a substantial healthcare burden on both the individual and society. One of the most significant shifts in the RA therapeutic landscape has occurred with the introduction of biological disease modifying anti-rheumatic drugs (bDMARDs). There are five classes of bDMARDs currently available, each with a different molecular target and subtle differences in their efficacy and safety profile. This review also describes the "real-world" use of bDMARDs and how they fit into the overall RA treatment guidelines.
\end{abstract}

Keywords: rheumatoid arthritis, biological therapies, bDMARDs

\section{Introduction}

Rheumatoid Arthritis (RA) is a worldwide disorder chiefly characterised by inflammation of synovial joints. Extra-articular manifestations are common including involvement of the skin, ocular, haematological, pulmonary and renal systems. ${ }^{1}$ A heightened cardiovascular risk also exists which closely follows disease activity. ${ }^{2}$ As the global prevalence of RA approximates $0.5 \%,{ }^{3}$ the disease poses a substantial healthcare burden on both the individual and society. Although RA remains incurable, the evolution of its management has led to unprecedented improvements in outcomes.

Previously, therapeutic options for RA were limited with non-steroidal antiinflammatory drugs (NSAIDs) and glucocorticoids forming the backbone of management. In the latter part of the 20th century treatment regimens expanded to include what are now known as conventional synthetic disease modifying antirheumatic drugs (csDMARDs) such as methotrexate, hydroxychloroquine and sulfasalazine which remain an integral part of the therapeutic paradigm. One of the most significant shifts in the RA therapeutic landscape, however, occurred in the late 1990s with the introduction of biological disease modifying anti-rheumatic drugs (bDMARDs). These genetically engineered monoclonal antibodies and receptor constructs were specifically designed to target key molecular mediators of the inflammatory process. ${ }^{4}$ Biosimilar drugs with the same targets have become available more recently, increasing the accessibility and affordability of this class of drug. Targeted synthetic disease modifying anti-rheumatic drugs (tsDMARDs) are the latest addition to the treatment armamentarium; however, discussion of these is beyond the scope of this paper.

To inform our narrative review, we conducted a limited literature review using PubMed and MEDLINE databases. We also reviewed the most recent guidelines
Correspondence: Andrew JK Ostor Cabrini Medical Centre, Melbourne, Victoria, Australia

Tel +6I 395094244

Email andrewostor@gmail.com 
published by the American College of Rheumatology and the European League Against Rheumatism.

\section{Classes of Biological DMARDs}

The classes of bDMARDs currently available for use in RA include tumour necrosis factor-alpha (TNF) inhibitors, the CD80/CD86 costimulation inhibitor abatacept, the interleukin-6 (IL-6) inhibitors, the CD-20 depleting agent rituximab and an anti-IL1 antibody.

\section{TNF Inhibitors}

The TNF inhibitors were the first bDMARDs approved for the treatment of RA. TNF-alpha is known to be a key cytokine in the pathogenesis of RA, with roles including the induction of other proinflammatory cytokines, activation of leukocytes, endothelial cells and synovial fibroblasts, suppression of regulatory $\mathrm{T}$ cells and osteoclast activation. $^{5}$ Five TNF inhibitors are currently available for use in RA - infliximab, adalimumab, golimumab, certolizumab pegol and etanercept. Etanercept is a TNFreceptor construct, whereas the others are monoclonal antibodies with certolizumab pegol being a pegylated fragment of the TNF inhibitor monoclonal antibody.

Whilst all bDMARDs have shown similar efficacy, TNF inhibitors are often chosen as the first line bDMARD in methotrexate non-responders due to longterm familiarity with their use, efficacy and safety profile. TNF inhibitors improve outcomes in patients with insufficient response to methotrexate, ${ }^{6-10}$ but have been found to have greater efficacy when combined with methotrexate. ${ }^{11}$ In the event treatment targets (see below) are not achieved with one TNF inhibitor, there is conflicting evidence as to whether switching to an alternate TNF inhibitor is as efficacious as using an agent from a different class. ${ }^{12,13}$ The most recent American College of Rheumatology guidelines now favour moving to a different drug class rather than sequential TNF inhibition. ${ }^{14}$ All the TNF inhibitors have comparable efficacy, with the choice of agent generally being dependent on patient preference for route of administration and frequency of treatment.

\section{T Cell Co-Stimulation Inhibitors}

Abatacept is a recombinant fusion protein comprising CTLA-4 and the Fe portion of IgG1. It acts to selectively inhibit $\mathrm{T}$ cell activation by binding to CD80 and CD86 on antigen presenting cells. It has also been demonstrated to have effects on other cells and processes involved in pathogenesis of RA including macrophage migration,
$\mathrm{B}$ cell activation and production of inflammatory mediators such as interleukins, C-reactive protein and interferon. ${ }^{15}$ Abatacept has demonstrated increased remission rates when compared to methotrexate alone, in both methotrexate-naïve patients and those with inadequate response to methotrexate. ${ }^{16,17}$ In those with an inadequate response to methotrexate, abatacept has comparable clinical benefit to TNF inhibitors when added to background methotrexate, ${ }^{18}$ whilst efficacy has also been seen in those with disease refractory to TNF inhibitors. ${ }^{19}$

\section{IL-6 Inhibitors}

Tocilizumab and sarilumab are antagonists of the IL-6 receptor, with IL-6 being a pivotal cytokine involved in the pathogenesis of RA. The IL-6 inhibitors have shown efficacy when added to methotrexate or as monotherapy in patients resistant to methotrexate, ${ }^{20}$ and in patients with insufficient response to TNF inhibitors. ${ }^{21}$ The IL-6 inhibitors have been demonstrated to have greater efficacy than TNF inhibitors when used as monotherapy without concurrent csDMARD, as demonstrated in head-to-head trials with adalimumab. ${ }^{22,23}$ This represents a role for these agents in patients in whom csDMARDs are either poorly tolerated or contraindicated. Similar to TNF inhibitors, switching from one IL-6 inhibitor to another after failure of the first is possible but in general an alternative class is preferred. $^{24}$

\section{CD-20 Depleting Antibodies}

Rituximab is a chimeric monoclonal antibody that binds to CD20 on B lymphocytes, thereby causing B cell depletion. B cell therapy in RA was developed with the aim of reducing the production of pathogenic autoantibodies; however, the exact mechanism by which the B cell depletion induced by rituximab translates to reduced disease activity in RA is not entirely understood. Overall response rates to rituximab are similar to that of TNF inhibitors, particularly amongst patients with seropositive RA. Rituximab is non-inferior to initial TNF inhibition in patients with seropositive RA and inadequate response to csDMARDs. ${ }^{25}$ In patients with inadequate response to one previous TNF inhibitor, switching to rituximab rather than an alternate TNF inhibitor is associated with greater improvement, particularly in seropositive patients. ${ }^{26}$ However, regional prescribing regulations often limit its availability as a first line bDMARD, with many countries requiring prior failure of a TNF inhibitor. Overall, its use is limited to the treatment of refractory RA. In patients 
with a previous history of lymphoproliferative malignancy rituximab remains a favourable option as it is also used in the treatment of lymphoma. ${ }^{14}$

\section{IL-I Inhibitors}

Anakinra is a recombinant human IL-1 receptor antagonist. Whilst it is licensed for the treatment of RA in several countries, it is less efficacious than other bDMARDs, ${ }^{27}$ and coupled with its unfavourable dosing schedule of daily subcutaneous injections, is infrequently used.

\section{Biosimilars}

bDMARDs are costly, representing a major barrier to their widespread use particularly in countries with challenged healthcare systems. Biosimilar drugs have thus been developed which are analogous to their originators. These drugs have been shown to have a comparable efficacy and safety profile to originator bDMARDs; ${ }^{28}$ however, their availability differs between countries. Biosimilars of infliximab, adalimumab, etanercept and rituximab have been developed and approved for use in RA in some countries and offer the potential to reduce health care costs and improve accessibility. ${ }^{28} \mathrm{~A}$ number of issues remain with integration of biosimilars into the market although cost pressures will likely prevail. With the increasing availability of biosimilars clinicians should be mindful that multiswitching between biosimilars, and switchbacks from biosimilar to bio-originators, is less well-studied at present. ${ }^{29}$

\section{Targeted Synthetic DMARDs}

Following the success of bDMARDs in the treatment of RA, the Janus kinase inhibitors were developed. These agents are classified as targeted synthetic DMARDs (tsDMARDs) and now have an established role in management paradigm of RA. Overall, they have similar efficacy $^{30}$ and safety profile to bDMARDs and are given orally. Discussion of these agents is beyond the scope of this review.

\section{Safety of Biological DMARDs}

It has been greatly reassuring to the rheumatology community that bDMARDs have been found to have an acceptable benefit-to-risk profile and are well tolerated in the long term. The main adverse event is an increased risk of infection as the cellular targets of these drugs are fundamental to host defense. ${ }^{31,32}$ The general infection risk also depends upon additional factors such as concomitant glucocorticoid use, patient age and comorbidities, as well as an underlying increased risk associated with RA itself. ${ }^{33}$ Infections of particular concern include latent tuberculosis reactivation, particularly with TNF inhibitors. ${ }^{34,35}$ Reactivation of hepatitis B virus has also been seen, the highest risk observed with rituximab. ${ }^{36}$ Additionally, there are rare reports of progressive multifocal leukoencephalopathy due to reactivation of John Cunningham virus in patients treated with rituximab. ${ }^{37}$ Abatacept, compared to other bDMARDs particularly TNF inhibitors, has been shown to carry a reduced risk of infection causing hospitalisation. $^{38}$

In the presence of severe, active infection of any aetiology, guidelines recommend against the initiation of bDMARDs. ${ }^{39}$ Coadministration of one class of bDMARD with another from a different class is not recommended due to an increased risk of infection. Clinicians should screen for latent infections with hepatitis B and C serology, chest radiograph plus interferon gamma release assay or tuberculin skin test. Further, a patient's risk for human immunodeficiency virus (HIV) infection should also be considered, with HIV serology being routinely requested prior to initiation of the bDMARD. ${ }^{39}$ To reduce the infection risk, guidelines specify that patients on bDMARDs should continue with national vaccination schedules including influenza and pneumococcal immunisations (although there may be an attenuated response) as well as the human papilloma virus vaccine for cervical cancer. Live attenuated vaccines (such as the live herpes zoster vaccine, yellow fever, measles, mumps, rubella), are contraindicated in patients taking a bDMARD. ${ }^{39}$

There is no confirmed increased risk of malignancy, including solid organ, lymphoma and melanoma, with the use of bDMARDs, although evidence is mixed and a slight increased risk for nonmelanoma skin cancer may exist. ${ }^{31,40,41}$ Patients on bDMARDs should be encouraged to comply with national cancer screening programs, including screening for skin cancer. Given its mode of action and other indications, rituximab may be favoured in patients with a history of lymphoproliferative malignancy. ${ }^{14}$ For patients with a history of malignancy, there is understandable hesitancy surrounding the use of bDMARDs due to the theoretical risk of recurrence. ${ }^{42}$ Current available data, however, suggest there is no increased risk of cancer recurrence upon initiation of bDMARDs for the treatment of RA. ${ }^{43}$ Real-world data suggest bDMARDs are not uncommonly continued or initiated following a diagnosis of solid organ malignancy, with TNF inhibitors being the most commonly initiated 
bDMARD. ${ }^{44}$ It should also be noted that TNF and IL-6 inhibitors have a role in the management of immune checkpoint inhibitor induced inflammatory arthritis. ${ }^{45,46}$ Patients with malignancy being treated with immunotherapy can experience severe disability due to immunerelated adverse effects such as inflammatory arthritis. In such situations, oncologists refer to rheumatologists to consider prescription of bDMARDs so that their patients can achieve an acceptable quality of life during their cancer treatment and after they have achieved remission. $^{45}$

Various non-infective adverse effects of individual bDMARDs exist and are outlined in greater detail in Table 1. Given the similar efficacy of bDMARDs in RA, a patient's comorbidities form an important consideration when selecting a bDMARD. TNF inhibitors are relatively contraindicated in patients with multiple sclerosis and New York Heart Association Class III or IV heart failure, with reports of exacerbations of both diseases. ${ }^{47,48}$ Regarding the IL-6 inhibitors, there is an increased risk of gastrointestinal perforation with tocilizumab, particularly in older patients with a history of diverticulitis. ${ }^{49}$

\section{Current Guidelines on Initiation, Tapering and Discontinuation of Biological DMARDs}

The European League Against Rheumatism (EULAR) and the American College of Rheumatology (ACR) have each published treatment guidelines for RA $;^{14,50}$ summarised in Table 2. With the emergence of further evidence the EULAR guidelines were revised in 2019 and the ACR guidelines updated in 2021.

Both sets of guidelines follow a "treat-to-target" strategy which has been another significant step-forward in the RA treatment paradigm. This approach involves the selection of a target (eg, disease remission) at pre-specified time points, with adaptation of therapy if the goal has not been achieved. ${ }^{4}$ Both EULAR and ACR have agreed-upon definitions of remission involving a combination of both clinical and biochemical criteria. ${ }^{51}$ If complete remission is not attainable, "low disease activity" is an acceptable alternative. Adjustment of a treatment regimen is recommended after three months in the absence of significant clinical improvement or after six months if remission is not achieved. ${ }^{4}$
Both guidelines recommend methotrexate monotherapy with supplemental folic acid as first-line therapy unless contraindicated or not tolerated, in which case the use of other csDMARDs are recommended. In patients with low disease activity, however, the ACR guidelines recommend first-line hydroxychloroquine or sulfasalazine over methotrexate. In the event of treatment failure using csDMARDs, each set of guidelines has subtle differences as to when to introduce bDMARDs or tsDMARDs. EULAR identifies a number of poor prognostic factors such as a high concentration of acute phase reactants or the presence of early erosions. In the presence of any one of these factors, the addition of a bDMARD or tsDMARD to the current treatment regimen is recommended. In the absence of poor prognostic factors, however, the addition of or change to an alternative csDMARD is recommended before considering advanced therapies. The ACR guidelines, in comparison, support the addition of a bDMARD or tsDMARD to methotrexate monotherapy over the addition of other csDMARDs except in patients with history of serious infection or nontuberculous mycobacterial lung disease, in which case the addition of csDMARDs is recommended. Neither guideline recommends one class of bDMARD or tsDMARD over another, except a conditional recommendation for rituximab in patients with a history of a lymphoproliferative disorder and against TNF inhibitors in patients with heart failure by the ACR. Neither guideline advocates the use of bDMARD monotherapy. It has been shown that the development of anti-drug antibodies and subsequent immunisation to biologic agents is not uncommon in patients with RA, particularly against TNF inhibitors. The combination of methotrexate to biologic agents reduces the production of these antibodies and improve treatment persistence. ${ }^{52}$ In the event a patient is unable to tolerate any csDMARD, however, EULAR recommends IL-6 inhibitors over other bDMARDs as monotherapy. If remission is not reached using one class of bDMARD or tsDMARD, the ACR guidelines recommend switching to bDMARD or tsDMARD of a different class, whereas this is not stipulated by EULAR.

In cases of persistent disease remission, tapering of bDMARDs and tsDMARDs may be considered especially when combined with csDMARDs. The guidelines do, however, emphasise the risk of relapse when tapering and therefore recommend an open discussion with patients and careful monitoring. 
Table I Summary of Biological DMARDs Used in Rheumatoid Arthritis

\begin{tabular}{|c|c|c|c|}
\hline Drug Class & Efficacy (ACR70*) & Adverse Effects & Contraindications ${ }^{\wedge}$ \\
\hline \multicolumn{4}{|l|}{ TNF- $\alpha$ inhibitor } \\
\hline $\begin{array}{l}\text { Adalimumab } \\
\text { 40mg SC fortnightly }\end{array}$ & \multirow{8}{*}{$\begin{array}{l}20-21 \%(\mathrm{MTX} \text { inadequate } \\
\text { responders) } \\
12 \%, 8,9 \\
\text { responders }^{12}\end{array}$} & \multirow{8}{*}{$\begin{array}{l}\text { Infections, TB reactivation, injection } \\
\text { site reactions, hypersensitivity } \\
\text { reactions, LFT derangements, } \\
\text { psoriasis, drug-induced lupus, blood } \\
\text { dyscrasias, malignancy (non- } \\
\text { melanomatous skin cancers, } \\
\text { lymphoma), exacerbation } \\
\text { demyelinating disease, exacerbation of } \\
\text { heart failure }\end{array}$} & \multirow{8}{*}{$\begin{array}{l}\text { Serious or untreated infections } \\
\text { including TB, current } \\
\text { malignancy, multiple sclerosis, } \\
\text { severe heart failure, } \\
\text { hypersensitivity }\end{array}$} \\
\hline $\begin{array}{l}\text { Certolizumab pegol } \\
200 \mathrm{mg} \text { SC fortnightly }\end{array}$ & & & \\
\hline Etanercept & & & \\
\hline $50 \mathrm{mg}$ SC weekly or $25 \mathrm{mg}$ twice & & & \\
\hline weekly & & & \\
\hline Golimumab & & & \\
\hline $50-100 \mathrm{mg}$ SC monthly & & & \\
\hline $\begin{array}{l}\text { Infliximab } \\
3-10 \mathrm{mg} / \mathrm{kg} \text { IV 4-8 weekly }\end{array}$ & & & \\
\hline \multicolumn{4}{|l|}{ IL-6 inhibitor } \\
\hline $\begin{array}{l}\text { Tocilizumab } \\
162 \mathrm{mg} \text { SC weekly or } 8 \mathrm{mg} / \mathrm{kg} \text { IV } \\
\text { monthly }\end{array}$ & \multirow{2}{*}{$\begin{array}{l}22 \%(\mathrm{MTX} \text { inadequate } \\
\text { responders) }{ }^{24} \\
12 \%(\mathrm{TNFi} \text { inadequate } \\
\text { responders) })^{21}\end{array}$} & \multirow{2}{*}{$\begin{array}{l}\text { Infections, injection site reactions, } \\
\text { hypersensitivity reactions, LFT } \\
\text { derangements, hyperlipidaemia, } \\
\text { neutropenia, diverticulitis and GI } \\
\text { perforation }\end{array}$} & \multirow[t]{2}{*}{$\begin{array}{l}\text { Serious or untreated } \\
\text { infections, hypersensitivity, } \\
\text { diverticulitis }\end{array}$} \\
\hline $\begin{array}{l}\text { Sarilumab } \\
150-200 \mathrm{mg} \text { SC fortnightly }\end{array}$ & & & \\
\hline \multicolumn{4}{|l|}{ CD20 depleting antibody } \\
\hline $\begin{array}{l}\text { Rituximab } \\
\text { IV } 2 \text { course dose } 500-1000 \mathrm{mg} \text {, } \\
\text { repeat after }>6 \text { months }\end{array}$ & $\begin{array}{l}20 \% \text { (MTX inadequate } \\
\text { responders })^{67} \\
12 \%(\text { TNFi inadequate } \\
\text { responders) }\end{array}$ & $\begin{array}{l}\text { Infections, hypersensitivity reactions, } \\
\text { cytopaenias, hepatitis B reactivation, } \\
\text { progressive multifocal } \\
\text { leukoencephalopathy }\end{array}$ & $\begin{array}{l}\text { Serious or untreated infections } \\
\text { including hepatitis B, } \\
\text { hypersensitivity }\end{array}$ \\
\hline \multicolumn{4}{|c|}{ CD80/86 costimulation inhibitor } \\
\hline $\begin{array}{l}\text { Abatacept } \\
125 \mathrm{mg} \text { SC weekly or IV infusion }\end{array}$ & $\begin{array}{l}21 \%(\mathrm{MTX} \text { inadequate } \\
\text { responders) } \\
10 \%(\mathrm{TNFi} \text { inadequate } \\
\text { responders) }\end{array}$ & $\begin{array}{l}\text { Infections, hypersensitivity reactions, } \\
\text { infusion reactions, leukopenia, } \\
\text { bronchitis }\end{array}$ & $\begin{array}{l}\text { Serious or untreated } \\
\text { infections, current malignancy, } \\
\text { hypersensitivity }\end{array}$ \\
\hline \multicolumn{4}{|l|}{ IL-I inhibitor } \\
\hline $\begin{array}{l}\text { Anakinra } \\
\text { I00mg SC daily }\end{array}$ & $\begin{array}{l}7 \% \text { (either MTX naïve or MTX } \\
\text { inadequate responders) }\end{array}$ & Infections, injection site reactions & $\begin{array}{l}\text { Serious or untreated } \\
\text { infections, hypersensitivity }\end{array}$ \\
\hline
\end{tabular}

Notes: Drug dosing, adverse effect profile and contraindications were adapted from the Australian Medicine Handbook ${ }^{69}$. The adverse effects listed are a selective and far from an exhaustive list. *ACR70 is a composite measure defined as an improvement of at least $70 \%$ in the number of tender and number of swollen joints, and at least a $70 \%$ improvement in three of the following five criteria: patient global assessment, physician global assessment, functional ability measure, visual analogue pain scale, and erythrocyte sedimentation rate or C-reactive protein. ACR70\% response rates correspond with a state of either remission or low disease activity and are used as surrogates of low disease activity. ${ }^{\wedge}$ Absolute or relative. 


\section{Use in Specific Circumstances}

Pregnancy

Whilst many patients experience improved disease activity during pregnancy, flares are common during the early post-partum period. TNF inhibitors may be continued during pregnancy; however, given differences in placental transfer due to variable molecular structure and half-life, the timing of cessation varies between drugs. For example, most guidelines recommend discontinuation of infliximab and adalimumab by 20 weeks gestation and etanercept by 32 weeks, ${ }^{53}$ whereas certolizumab does not cross the placenta and can be safely continued throughout pregnancy. ${ }^{54}$ Infants exposed to TNF inhibitors in utero should not receive live vaccines (eg, rotavirus) for the first six months of life. Other bDMARDs such as rituximab, abatacept and the IL- 6 inhibitors contain immunoglobulin and therefore cross the placenta in increasing amounts after the first trimester; whilst there is no data to suggest evidence of harm when used before conception or in the first trimester, lack of safety data prevents consensus recommendations and at present they are contraindicated. ${ }^{53}$

\section{COVID-19}

Despite an assumed increased risk, observational data generally report similar rates of infection, hospitalisation and death in patients with COVID-19 infection on bDMARDs compared with controls. ${ }^{55-58}$ Some studies however suggest a possible increased risk of poorer outcomes. ${ }^{59}$ Regardless, ACR guidelines propose bDMARDs be withheld in the setting of COVID-19 infection, although IL-6 receptor inhibitors may be continued in select circumstances given evidence of its benefit in the treatment of severe COVID-19 infection in the general population. ${ }^{60,61}$ When considering COVID-19 vaccination whilst on bDMARDs for rheumatic disease, concerns lie in the potential blunting of the immune response in patients on immunomodulatory medications. Recommendations from various bodies differ slightly and depend on both the choice of vaccine and the specific bDMARD alongside its frequency of administration. The ACR guidelines advise that TNF inhibitors, IL-6 receptor inhibitors and IL-1 antagonism can be continued without modification, whereas vaccination should be more specifically timed in patients on abatacept and rituximab. ${ }^{62}$

\section{The Real-World Use of bDMARDs}

TNF inhibitors are typically selected as a first-line biologic agent as this class was the first of the bDMARDs introduced and is therefore the most studied and familiar to clinicians. Patient populations in randomised controlled trials, however, poorly reflect those treated in the realworld. Data from large observational studies on drug retention or discontinuation may therefore be considered a surrogate for both safety and effectiveness in the true RA population.

In a retrospective observational study from Australia, ${ }^{63}$ the discontinuation rate of TNF inhibitors was $51 \%$ over seven years. Of all the bDMARDs, certolizumab had the highest discontinuation rate within six months of initiation; the most commonly cited reason being a lack of efficacy. Another commonly cited reason for drug discontinuation was adverse effects, for which infliximab was most commonly ceased. Rituximab was discontinued in only $28 \%$ of cases, whereas the other nonTNF inhibitor bDMARDs abatacept and tocilizumab had similar cessation rates to TNF inhibitors, at $47 \%$ and $52 \%$, respectively. High TNF inhibitor discontinuation rates were also demonstrated in a Japanese cohort; ${ }^{64}$ albeit somewhat lower than the Australian population. The discontinuation rate of TNF inhibitors was between $25 \%$ and $34 \%$ in bDMARD-naïve individuals. Again, certolizumab was most commonly stopped due to a lack of effectiveness in this population, while etanercept was most commonly ceased due to adverse effects. The discontinuation rate of non-TNF inhibitor bDMARDs abatacept and tocilizumab were $18.3 \%$ and $23.5 \%$, respectively. In a Canadian study ${ }^{65}$ it was found that the retention rate for TNF inhibitors was higher than nonTNF inhibitors; however, there was no significant difference between the groups for switching agent due to lack of efficacy.

\section{Biological DMARDs Under Development}

As per treat-to-target strategies, clinical remission, or at least low disease activity, are now widely accepted management goals in the treatment of RA. This is a realistic goal for a significant proportion of patients with RA, in stark contrast to previously when RA was a highly disabling disease with limited therapeutic options. However, for the remaining patients who struggle to achieve treatment targets, additional therapies are required. Fortunately, the ongoing improved understanding of the pathogenesis of RA is facilitating exploration of new molecular targets. Approximately seventy potential drug targets are currently 
Table 2 Summary of EULAR and ACR RA Treatment Guidelines

\begin{tabular}{|c|c|c|}
\hline & EULAR & ACR \\
\hline $\begin{array}{l}\text { First-line } \\
\text { (Immediately at diagnosis) }\end{array}$ & $\begin{array}{l}\text { Start csDMARD } \\
\text { (MTX preferred, if intolerant or } \\
\text { contraindicated use another csDMARD) }\end{array}$ & $\begin{array}{l}\text { Start csDMARD } \\
\text { (MTX preferred in moderate-to-high disease activity, } \\
\text { hydroxychloroquine then sulfasalazine preferred in } \\
\text { low disease activity) }\end{array}$ \\
\hline $\begin{array}{l}\text { Second line } \\
\text { (At three months if no significant } \\
\text { improvement, or at six months if } \\
\text { complete remission not attained) }\end{array}$ & $\begin{array}{l}\text { If no poor prognostic factors*: add second } \\
\text { csDMARD } \\
\text { or } \\
\text { If poor prognostic factors*: add bDMARD or } \\
\text { tsDMARD } \\
\text { or } \\
\text { If poor prognostic factors* and unable to } \\
\text { tolerate csDMARDs: preference IL-6i or } \\
\text { tsDMARD monotherapy. }\end{array}$ & $\begin{array}{l}\text { Add any bDMARD or tsDMARD to csDMARD } \\
\text { or } \\
\text { If previous serious infection in the previous I } 2 \\
\text { months or history of NTMB lung disease: } \\
\text { add second csDMARD } \\
\text { or } \\
\text { If history of heart failure: add non-TNFi bDMARD or } \\
\text { tsDMARD to csDMARD } \\
\text { or } \\
\text { If history of lymphoproliferative disorder: add } \\
\text { rituximab to csDMARD }\end{array}$ \\
\hline $\begin{array}{l}\text { Third line and beyond } \\
\text { (At nine months if no significant } \\
\text { improvement, or at twelve months if } \\
\text { complete remission not attained) }\end{array}$ & $\begin{array}{l}\text { Add bDMARD or tsDMARD to current } \\
\text { csDMARD regimen. } \\
\text { or } \\
\text { Change to another bDMARD or tsDMARD in } \\
\text { combination with continued csDMARD } \\
\text { or } \\
\text { If failure of TNFi bDMARD: switch to another } \\
\text { TNFi bDMARD, or non-TNFi bDMARD or } \\
\text { tsDMARD }\end{array}$ & $\begin{array}{l}\text { If failure of bDMARD or tsDMARD, change to } \\
\text { a bDMARD or tsDMARD of a different class, in } \\
\text { combination with continued csDMARD }\end{array}$ \\
\hline $\begin{array}{l}\text { Remission } \\
\text { (After six months of complete } \\
\text { remission) }\end{array}$ & $\begin{array}{l}\text { Consider tapering bDMARD or tsDMARD } \\
\text { first, continue csDMARD. } \\
\text { If } 6 \text { months remission on csDMARD, consider } \\
\text { tapering csDMARD but beware of relapse risk. }\end{array}$ & $\begin{array}{l}\text { Continuation of all DMARDs is recommended, even } \\
\text { if remission is achieved (and if this is not an option } \\
\text { tapering is recommended over discontinuation) }\end{array}$ \\
\hline Additional information & $\begin{array}{l}\text { Short-term glucocorticoids should be } \\
\text { considered when initiating or changing } \\
\text { csDMARDs, but taper as quickly as possible }\end{array}$ & $\begin{array}{l}\text { Initiation of csDMARDs without short-term } \\
\text { glucocorticoids is recommended over doing so with } \\
\text { glucocorticoids }\end{array}$ \\
\hline
\end{tabular}

Notes: *Poor prognostic factors $=$ high number of swollen joints, high level of acute phase reactants, presence of early erosions, rheumatoid factor or anti-cycliccitrullinated peptide positivity, persistently high disease activity on csDMARD. Data from these studies. ${ }^{14,50}$

Abbreviations: csDMARD, conventional synthetic disease modifying anti-rheumatic drug; MTX, methotrexate; bDMARD, biological disease modifying anti-rheumatic drug; tsDMARD, targeted synthetic disease modifying anti-rheumatic drug; NTMB, non-tuberculous mycobacterial lung disease; IL6i, interleukin 6 inhibitor; TNFi, tumour necrosis factor inhibitor.

in development, with the majority of these being bDMARDs and tsDMARDs. ${ }^{66}$ Promising bDMARD targets include cytokines such as interleukins and granulocyte-monocyte colony stimulating factor, transmembrane activator and calcium modulator and cyclophilin ligand interactor (TACI) which is involved in B cell differentiation and proliferation, and agents targeting $\mathrm{T}$ cell activation or B and T cell costimulation. ${ }^{66}$

Further research into potential biomarkers that act as predictors of response to treatment is also required to facilitate precision medicine. At present, when selecting a targeted treatment, a trial-and-error approach is adopted taking into consideration patient factors and drug preference. The discovery of biomarkers predicting medication response will simplify management pathways, improve outcomes and reduce healthcare costs.

\section{Conclusion}

The advent of bDMARDs has dramatically altered the treatment landscape of RA. Disease remission or low disease activity are now achievable goals for many patients who have access to these therapeutics. The risk benefit for 
bDMARDs is firmly established with long-term efficacy and safety data for the differing biologic classes. There is no question bDMARDs will remain integral to the management of patients with RA for the foreseeable future in order to optimise outcomes.

\section{Disclosure}

The authors have no conflicts of interest in regard to this work.

\section{References}

1. Aletaha D, Smolen J. Diagnosis and management of rheumatoid arthritis: a review. JAMA. 2018;320(13):1360-1372. doi:10.1001/ jama.2018.13103

2. Crowson CS, Rollefstad S, Ikdahl E, et al. Impact of risk factors associated with cardiovascular outcomes in patients with rheumatoid arthritis. Ann Rheum Dis. 2018;77(1):48-54. doi:10.1136/annrheumdis-2017-211735

3. Almutair K, Nossent J, Preen D, Keen H, Inderjeeth C. The global prevalence of rheumatoid arthritis: a meta-analysis based on a systematic review. Rheumatol Int. 2021;41(5):863-877. doi:10.1007/s00296-020-04731-0

4. Smolen J, Aaletaha D, Barton A, et al. Rheumatoid arthritis. Nat Rev Dis Primers. 2018;4:18001. doi:10.1038/nrdp.2018.1

5. Brennan FM, Maini RN, Feldmann M. TNF alpha - a pivotal role in rheumatoid arthritis? Br J Rheumtol. 1992;31(5):293. doi:10.1093/ rheumatology/31.5.293

6. Keystone E, Genovese M, Klareskog L, et al. Golimumab, a human antibody to tumour necrosis factor \{alpha\} given by monthly subcutaneous injections, in active rheumatoid arthritis despite methotrexate therapy: the GO-FORWARD Study. Ann Rheum Dis. 2009;68 (6):789-796. doi:10.1136/ard.2008.099010

7. Maini R, St Clair E, Breedveld F, et al. Infliximab (chimeric antitumour necrosis factor alpha monoclonal antibody) versus placebo in rheumatoid arthritis patients receiving concomitant methotrexate: a randomized Phase III trial. Lancet. 1999;354(9194):1932-1939. doi:10.1016/s0140-6736(99)05246-0

8. Keystone E, Kavanaugh A, Sharp J, et al. Radiographic, clinical, and functional outcomes of treatment with Adalimumab (a human antitumor necrosis factor monoclonal antibody) in patients with active rheumatoid arthritis receiving concomitant methotrexate therapy. A randomized, placebo-controlled, 52-week trial. Arthritis Rheum. 2004;50(5):1400-1411. doi:10.1002/art.20217

9. Keystone E, van der Heijde D, Mason D, et al. Certolizumab pegol plus methotrexate is significantly more effective than placebo plus methotrexate in active rheumatoid arthritis: findings of a fiftytwo-week, Phase III, multicenter, randomized, double-blind, placebocontrolled, parallel-group study. Arthritis Rheum. 2008;58 (11):3319-3329. doi:10.1002/art.23964

10. Weinblatt M, Kremer J, Bankhurst A, et al. A trial of etanercept, a recombinant tumour necrosis factor receptor: fcfusion protein, in patients with rheumatoid arthritis receiving methotrexate. $N$ Engl J Med. 1999;340(4):253-259. doi:10.1056/NEJM199901283400401

11. Breedveld FC, Weisman MH, Kavanaugh AF, et al. The PREMIER study - a multicenter, randomized, double-blind clinical trial of combination therapy with adalimumab plus methotrexate versus methotrexate alone or adalimumab alone in patients with early, aggressive rheumatoid arthritis who had not had previous methotrexate treatment. Arthritis Rheum. 2006;54(1):26-37. doi:10.1002/art.21519
12. Smolen JS, Kay J, Doyle MK, et al. Golimumab in patients with active rheumatoid arthritis after treatment with tumour necrosis factor alpha inhibitors (GO-AFTER study): a multicentre, randomised, double-blind, placebo-controlled, phase III trial. Lancet. 2009;374 (9685):210-221. doi:10.1016/S0140-6736(09)60506-7

13. Gottenberg JE, Brocq O, Perdriger A, et al. Non-TNF-targeted biologic vs a second anti-TNF drug to treat rheumatoid arthritis in patients with insufficient response to a first anti-TNF drug: a randomized clinical trial. JAMA. 2016;316(11):1172-1180. doi:10.1001/jama.2016.13512

14. Fraenkel L, Bathon J, England B, et al. 2021 American College of Rheumatology guideline for the treatment of rheumatoid arthritis. Arthritis Care Res. 2021;73(7):924-939. doi:10.1002/acr.24596

15. Dubois E, Cohen A. Abatacept. Br J Clin Pharmacol. 2009;68 (4):480-481. doi:10.1111/j.1365-2125.2009.03502.x

16. Westhovens R, Robles M, Zimenes AC, et al. Clinical efficacy and safety of abatacept in methotrexate-naive patients with early rheumatoid arthritis and poor prognostic factors. Ann Rheum Dis. 2009;68 (12):1870-1877. doi:10.1136/ard.2008.101121

17. Kremer K, Genant H, Moreland L, et al. Effects of abatacept in patients with methotrexate-resistant active rheumatoid arthritis: a randomized trial. Ann Intern Med. 2006;144(12):865-876. doi:10.7326/0003-4819-144-12-200606200-00003

18. Schiff M, Keiserman M, Codding C, et al. Efficacy and safety of abatacept or infliximab vs placebo in ATTEST: a phase III, multi-centre, randomised, double-blind, placebo-controlled study in patients with rheumatoid arthritis and an inadequate response to methotrexate. Ann Rheum Dis. 2008;67(8):1096-1103. doi:10.1136/ard.2007.080002

19. Genovese MC, Becker JC, Schiff M, et al. Abatacept for rheumatoid arthritis refractory to tumor necrosis factor alpha inhibition. $N$ Engl J Med. 2005;353(11):1114-1123. doi:10.1056/NEJMoa050524

20. Burmester GR, Rigby WF, van Vollenhoven RF, et al. Tocilizumab in early progressive rheumatoid arthritis: FUNCTION, a randomised controlled trial. Ann Rheum Dis. 2015;75(6):1081-1091. doi:10.1136/annrheumdis2015-207628

21. Emery P, Keystone E, Tony HP, et al. IL-6 receptor inhibition with tocilizumab improves treatment outcomes in patients with rheumatoid arthritis refractory to anti-tumour necrosis factor biologicals: results from a 24-week multicentre randomised placebo-controlled trial. Ann Rheum Dis. 2008;67(11):1516-1523. doi:10.1136/ard.2008.09293

22. Gabay C, Emery P, van Vollenhoven R, et al. Tocilizumab monotherapy versus adalimumab monotherapy for treatment of rheumatoid arthritis (ADACTA): a randomised, double-blind, controlled Phase 4 trial. Lancet. $\quad 2013 ; 381(9877): 1541-1550 . \quad$ doi:10.1016/S0140-6736(13) 60250-0

23. Burmester GR, Lin Y, Patel R, et al. Efficacy and safety of sarilumab monotherapy versus adalimumab monotherapy for the treatment of patients with active rheumatoid arthritis (MONARCH): a randomised, double-blind, parallel-group phase III trial. Ann Rheum Dis. 2017;76(5):840-847. doi:10.1136/annrheumdis-2016-210310

24. Vershueren P, Emery P, van Hoogstraten H, et al. Efficacy of sarilumab in patients with rheumatoid arthritis with and without previous response to tocilizumab. Ann Rheum Dis. 2018;77(supp 2):327-328. doi:10.1136/annrheumdis-2018-eular.1376

25. Porter D, van Melckebeke J, Dale J, et al. Tumour necrosis factor inhibition versus rituximab for patients with rheumatoid arthritis who require biological treatment (ORBIT): an open-label, randomised controlled, non-inferiority, trial. Lancet. 2016;18(388):239-247. doi:10.1016/S0140-6736(16)00380-9

26. Emery P, Gottenberg JE, Rubbert-Roth A, et al. Rituximab versus an alternative TNF inhibitor in patients with rheumatoid arthritis who failed to respond to a single previous TNF inhibitor: SWITCH-RA, a global, observational, comparative effectiveness study. Ann Rheum Dis. 2015;74(6):979-984. doi:10.1136/annrheumdis-2013-203993 
27. Merten M, Singh J. Anakinra for rheumatoid arthritis. Cochrane Database Syst Rev. 2009. doi:10.1002/14651858.CD005121.pub3

28. Smolen J, Goncalves J, Quinn M, Benedetti F, Lee JY. Era of biosimilars in rheumatology: reshaping the healthcare environment. RMD Open. 2019;5(1):e00900. doi:10.1136/rmdopen-2019-000900

29. Feagan BG, Marabani M, Wu JJ, Facacin F, Spronk C, CastanedaHernandez G. The challenges of switching therapies in an evolving multiple biosimilars landscape: a narrative review of current evidence. Adv Ther. 2020;37(11):4491-4518. doi:10.1007/s12325020-01472-1

30. Van Vollenhoven RF, Fleischmann R, Cohen S, et al. Tofacitinib or adalimumab versus placebo in rheumatoid arthritis. $N$ Engl $J$ Med. 2012;367(6):508-519. doi:10.1056/NEJMoa1112072

31. Ramiro S, Gaujoux-Viala C, Nam JL, et al. Safety of synthetic and biological DMARDs: a systematic literature review informing the 2013 update of the EULAR recommendations for management of rheumatoid arthritis. Ann Rheum Dis. 2014;73(3):529-535. doi:10.1136/annrheumdis-2013-204575

32. Ehlers S. Role of tumour necrosis factor (TNF) in host defence against tuberculosis: implications for immunotherapies targeting TNF. Ann Rheum Dis. 2003;62(2):37-42. doi:10.1136/ard.62. suppl_2.ii37

33. Listing J, Gerhold K, Zink A. The risk of infection associated with rheumatoid arthritis, with its comorbidity and treatment Rheumatology. 2012;51(1):53-61. doi:10.1093/rheumatology/kes305

34. Askling J, Fored CM, Brandt L, et al. Risk and case characteristics of tuberculosis in rheumatoid arthritis associated with tumor necrosis factor antagonists in Sweden. Arthritis Rheum. 2005;53 (7):1986-1992. doi:10.1002/art.21137

35. Dixon WG, Hyrich KL, Watson KD, et al. Drug-specific risk of tuberculosis in patients with rheumatoid arthritis treated with anti-TNF therapy: results from the British Society for Rheumatology Biologics Register (BSRBR). Ann Rheum Dis. 2010;69(3):522-528. doi:10.1136/ard.2009.118935

36. Mitka M. FDA: increased HBV reactivation risk with ofatumumb or rituximab. JAMA. 2012;310(16):1664. doi:10.1001/ jama.2013.281115

37. Clifford DB, Ances B, Costello C, et al. Rituximab-associated progressive multifocal leukoencephalopathy in rheumatoid arthritis. Arch Neurol. 2001;68(9):1156-1164. doi:10.1001/archneurol.2011.103

38. Chen SK, Liao KP, Liu J, Kim SC. Risk of hospitalized infection and initiation of abatacept versus tumor necrosis factor inhibitors among patients with rheumatoid arthritis: a propensity score-matched cohort study. Arthritis Care Res. 2020;72(1):9-17. doi:10.1002/acr.23824

39. Holroyd CR, Seth R, Bukhari M, et al. The British Society for Rheumatology biologic DMARD safety guidelines in inflammatory arthritis. Rheumatology. 2019;58(2):e3-e42. doi:10.1093/rheumatology/key208

40. Mercer LK, Askling J, Raaschou P, et al. Risk of invasive melanoma in patients with rheumatoid arthritis treated with biologics: results from a collaborative project of 11 European biologic registries. Ann Rheum Dis. 2017;76(2):386-391. doi:10.1136/annrheumdis-2016209285

41. Wang KL, Yin WJ, Zhou LY, et al. Risk of non-melanoma skin cancer for rheumatoid arthritis patients receiving TNF antagonist: a systematic review and meta-analysis. Clin Rheumatol. 2020;39 (3):769-778. doi:10.1007/s10067-019-04865-y

42. Chatzidionysiou K, Delcoigne B, Frisell T, et al. How do we use biologics in rheumatoid arthritis patients with a history of malignancy? An assessment of treatment patterns using Scandinavian registers. RMD Open. 2020;6(2):e001363. doi:10.1136/rmdopen2020-001363

43. Regierer AC, Strangfeld A. Rheumatoid arthritis treatment in patients with a history of cancer. Curr Opin Rheumatol. 2018;30(3):288-294. doi:10.1097/BOR.0000000000000492
44. Pappas D, Rebello S, Liu M, et al. Therapy with biologic agents after diagnosis of solid malignancies: results from the corrona registry. J Rheumatol. 2019;46(11):1438-1444. doi:10.3899/jrheum.171457

45. Brahmer JR, Lacchetti C, Schneider BJ, et al. Management of immune-related adverse events in patients treated with immune checkpoint inhibitor therapy: American society of clinical oncology clinic practice guideline. J Clin Oncol. 2018;36(17):1714-1768. doi:10.1200/JCO.2017.77.6385

46. Chen AY, Wolchok JD, Bass AR. TNF in the era of immune checkpoint inhibitors: friend or foe? Nat Rev Rheumatol. 2021;17 (4):213-223. doi:10.1038/s41584-021-00584-4

47. Mohan N, Edwards ET, Cupps TR, et al. Demyelination occurring during anti-tumor necrosis factor alpha therapy for inflammatory arthritides. Arthritis Rheum. 2001;44(12):2862-2869. doi:10.1002/ 1529-0131(200112)44:12<2862::aid-art474>3.0.co;2-w

48. Kwon HJ, Cote TR, Cuffe MS, Kramer JM, Braun MM. Case reports of heart failure after therapy with a tumor necrosis factor antagonist. Ann Intern Med. 2003;138(10):807-811. doi:10.7326/0003-4819138-10-200305200-00008

49. Strangfeld A, Richter A, Siegmund B, et al. Risk for lower intestinal perforations in patients with rheumatoid arthritis treated with tocilizumab in comparison to treatment with other biologic or conventional synthetic DMARDs. Ann Rheum Dis. 2017;76(3):504-510. doi:10.1136/annrheumdis-2016-209773

50. Smolen JS, Landewe RB, Bijlsma JW, et al. EULAR recommendations for the management of rheumatoid arthritis with synthetic and biological disease-modifying antirheumatic drugs: 2019 update. Ann Rheum Dis. 2019;79(6):685-699. doi:10.1136/annrheumdis-2019-216655

51. Bykerk VP, Massarotti EM. The new ACR/EULAR remission criteria: rationale for developing new criteria for remission. Rheumatology. 2012;51(supp6):vi16-vi20. doi:10.1093/rheumatology/kes 281

52. Schaeverbeke T, Truchetet ME, Kostine M, Barnetche T, Bannwarth B, Richez C. Immunogenicity of biologic agents in rheumatoid arthritis patients: lessons for clinical practice. Rheumatology. 2016;55(2):210-220. doi:10.1093/rheumatology/kev277

53. Skorpen CG, Hoeltzenbein M, Rincani A, et al. The EULAR points to consider for use of antirheumatic drugs before pregnancy, and during pregnancy and lactation. Ann Rheum Dis. 2015;75 (5):795-810. doi:10.1136/annrheumdis-2015-208840

54. Mariette X, Forger F, Abraham B, et al. Lack of placental transfer of certolizumab pegol during pregnancy: results from CRIB, a prospective, postmarketing, pharmacokinetic study. Ann Rheum Dis. 2017;77(2):228-233. doi:10.1136/annrheumdis-2017-212196

55. Monti S, Balduzzi S, Delvino P, Bellis E, Quadrelli VS, Montecucco C. Clinical course of COVID-19 in a series of patients with chronic arthritis treated with immunosuppressive targeted therapies. Ann Rheum Dis. 2020;79(5):667-668. doi:10.1136/annrheumdis-2020-217424

56. Conticini E, Bargagli E, Bardelli M, et al. COVID-19 pneumonia in a large cohort of patients treated with biological and targeted synthetic antirheumatic drugs. Ann Rheum Dis. 2021;80(2):e14. doi:10.1136/annrheumdis-2020-217681

57. Haberman R, Axelrad J, Chen A, et al. COVID-19 in immune-mediated inflammatory diseases - case series from New York. $\quad N \quad$ Engl $J$ Med. 2020;383(1):85-88. doi:10.1056/ NEJMc2009567

58. Gianfrancesco M, Hyrich KL, Al-Adely S, et al. Characteristics associated with hospitalisation for COVID-19 in people with rheumatic disease: data from the COVID-19 global rheumatology alliance physician-reported registry. Ann Rheum Dis. 2020;79(7):859-866. doi:10.1136/annrheumdis-2020-217871

59. Damiani G, Pacifico A, Bragazzi NL, Malagoli P. Biologics increase the risk of SARS-CoV-2 infection and hospitalization, but not ICU admission and death: real-life data from a large cohort during red-zone declaration. Dermatol Ther. 2020;33(5):e13475. doi:10.1111/dth. 13475 
60. Mikuls TR, Johnson SR, Fraenkel L, et al. American College of Rheumatology guidance for the management of rheumatic disease in adult patients during the COVID-19 pandemic: version 3. Arthritis Rheumatol. 2021;73(2):e1-e12. doi:10.1002/art.41596

61. RECOVERY Collaborative Group. Tocilizumab in patients admitted to hospital with COVID-19 (RECOVERY): a randomized, controlled, open-label, platform trial. Lancet. 2021;397(10285):1637-1645. doi:10.1016/S0140-6736(21)00676-0.

62. Curtis JR, Johnson SR, Anthony DD, et al. American College of Rheumatology guidance for COVID-19 vaccination in patients with rheumatic and musculoskeletal diseases: version 1. Arthritis Rheumatol. 2021;73(7):1093-1107. doi:10.1002/art.41734

63. Youssef P, Marcal B, Button P, et al. Reasons for biologic and targeted synthetic disease-modifying antirheumatic drug cessation and persistence of second-line treatment in a rheumatoid arthritis dataset. $J$ Rheumatol. 2020;47(8):1174-1181. doi:10.3899/ jrheum. 190535

64. Ebina K, Hirano T, Maeda Y, et al. Drug retention of 7 biologics and tofacitinib in biologics-naïve and biologics-switched patients with rheumatoid arthritis: the ANSWER cohort study. Arthritis Res Ther. 2020;22(1):142. doi:10.1186/s13075-020-02232-w

65. Movaahedi M, Couta S, Cesta C, et al. Time to discontinuation of biologic therapy by mechanism of action in rheumatoid arthritis: results from the Ontario best practice research initiative (OBRI) cohort. Ann Rheum Dis. 2018;77(supp 2):958. doi:10.1136/ annrheumdis-2018-eular.2131
66. Blaess J, Walther J, Petitdemange A, et al. Immunosuppressive agents for rheumatoid arthritis: a systematic review of clinical trials and their current development stage. Ther Adv Musculoskelet Dis. 2020;12:1759720X20959971. doi:10.1177/1759720X20959971

67. Emery P, Fleischmann R, Filipowicz-Sosnowska A, et al. The efficacy and safety of rituximab in patients with active rheumatoid arthritis despite methotrexate treatment: results of a phase IIB randomized, double-blind, placebo-controlled, dose-ranging trial. Arthritis Rheum. 2006;54(5):1390-1400. doi:10.1002/art.21778

68. Cohen S, Emery P, Greenwald M, et al. Rituximab for rheumatoid arthritis refractory to anti-tumor necrosis factor therapy: results of a multicenter, randomized, double-blind, placebo-controlled, phase III trial evaluating primary efficacy and safety at twenty-four weeks. Arthritis Rheum. 2006;54(9):2793-2806. doi:10.1002/ art. 22025

69. Gary M.H. Misan. Australian Medicines Handbook 2020. Adelaide: Australian Medicines Handbook Pty Ltd; July, 2020. Available from https://amhonline.amh.net.au/. Accessed August 3, 2021.

\section{Publish your work in this journal}

Biologics: Targets and Therapy is an international, peer-reviewed journal focusing on the patho-physiological rationale for and clinical application of Biologic agents in the management of autoimmune diseases, cancers or other pathologies where a molecular target can be identified. This journal is indexed on PubMed Central, CAS, EMBase,
Scopus and the Elsevier Bibliographic databases. The manuscript management system is completely online and includes a very quick and fair peer-review system, which is all easy to use. Visit http://www.dovepress.com/testimonials.php to read real quotes from published authors. 